\title{
Levosimendan usage in patients with left ventricle dysfunction in coronary artery bypass graft surgery
}

\author{
Habib Cakir ${ }^{1 *}$, Funda Tor ${ }^{2}$, Hasan Uncu ${ }^{2}$, Ozcan Gur ${ }^{3}$, Mehmet Acipayam ${ }^{4}$, Ozsoyler Ibrahim ${ }^{2}$ \\ ${ }^{1}$ Cardiovascular Surgery, Katip Celebi University Ataturk Education and Training Hospital, Izmir, Turkey \\ ${ }^{2}$ Cardiovascular Surgery, Adana Numune Education and Training Hospital, Adana, Turkey \\ ${ }^{3}$ Cardiovascular Surgery, Namik Kemal University Medicine Faculty, Tekirdag, Turkey \\ ${ }^{4}$ Cardiovascular Surgery, Mustafa Kemal University Medicine Faculty, Hatay, Turkey \\ Email: "habibcakir35@hotmail.com
}

Received 6 August 2012; revised 17 September 2012; accepted 25 September 2012

\begin{abstract}
Introduction: In this study we explicated early results of patients (the patients in whom levosimendan was used) who underwent coronary artery bypass graft surgery with ejection fraction $35 \%$ or less. We compared this group with the patients in whom levosimendan was not used. Material and Methods: 97 patients who have $35 \%$ ejection fraction or less taken to isolated coronary artery bypass surgery between January 2009 and December 2011 in our clinic are chosen for this study retrospectively. We compared the patients in whom levosimendan was used with the patients in whom levosimendan was not used. Levosimendan (Simdax, Abbott) has been used according to surgeon's decision in patients. Results: The mean age of group 1 was $62.3 \pm 7.6$, and the mean age of group 2 was $59.3 \pm 10.5(p>0.05)$. It was detected that the average ejection fraction was less in group 1 $(p<0.05)$. There were no statistically significant difference between the two groups in terms of demand for inotropics, demand for intraaortic balloon pump, revision (because of bleeding), atrial fibrillation, discharging intervals, intensive care unit time, cross clamp and cardiopulmonary bypass time $(p>0.05)$. It was found that need for blood transfusion were less in group 1 than group $2(p<0.05)$. There were no statistically significant difference between the two groups in terms of mortality $(p>0.05)$. Conclusion: We consider levosimendan reduces need for blood transfusion in coronary artery bypass graft surgery. This results may change with increasing number of patients so we consider that multicenter larger study is needed.
\end{abstract}

Keywords: Levosimendan; Mortality; Coronary Artery Bypass Surgery

*Corresponding author.

\section{INTRODUCTION}

Levosimendan is a new phosphodiesterase-inhibitor positive inotropic agent [1]. Levosimendan has anti-stunning effect mediated by calcium sensitization of contractile proteins. In addition, it has vasodilatory and anti-ischaemic effects mediated by the opening of ATP-sensitive potassium channels [2]. Because of its cardioprotective effect, levosimendan has been used commonly in patients with low ejection fraction so far. It has been declared that myocardial damage has been diminished with levosimendan usage in coronary artery bypass surgery [2].

In this study we reported early results of the patients receiving levosimendan that underwent coronary artery bypass grafting surgery with ejection fraction $35 \%$ or less. We compared this group with the patients not receiving levosimendan.

\section{MATERIAL AND METHODS}

97 Patients who have 35\% ejection fraction or less taken to isolated coronary artery bypass surgery between January 2009 and December 2011 in our clinic are chosen for this study retrospectively. We compared the patients in whom levosimendan was used (group $1, \mathrm{n}=13$ ) with the patients in whom levosimendan was not used (group 2, $\mathrm{n}=$ 84).

Patients demanding carotid or valvular surgery were excluded from study. The antiplatelet and anticoagulant therapy were stopped 7 days before the operation. Routine transthoracic echocardiography was carried out in all patients before surgery and the ejection fraction was calculated by Simpsons method. The viability tests have not been performed. Surgery decision has been had according to coronary anatomy in patients with low ejection fraction. Levosimendan (Simdax, Abbott) has been used according to surgeon's decision in patients. Levosimendan perfusion was begun before 12 hours from surgery in the intensive care unit in this patients. First 10 minutes, 
levosimendan was used total $24 \mathrm{mg} / \mathrm{kg}$, after it was used $0.1 \mathrm{mg} / \mathrm{kg} /$ minute. It was stopped postoperative 12 hours. For induction of anesthesia, fenthanyl citrate (Fentanyl Citrate, Abott) and midasolam (Dormicum, Roche) were and sevofluorane (Sevorane, Abott) and vercuronium bromide (Norcuron, Organon) were used for maintanence. Coronary artery bypass graft was applied either at the beating heart or under cardiopulmonary bypass according to surgeon's decision. $2 \mathrm{mg} / \mathrm{kg}$ Heparin (Nevparin, Mustafa Nevzat) was used in beating heart operations and $4 \mathrm{mg} / \mathrm{kg}$ heparin was used under cardiopulmonary bypass operations. In operations under cardiopulmonary bypass, mild systemic hypothermia was applied and cardiac arrest was maintained by warm blood cardioplegia given through the aortic root antegrade. Cardioplegia given through the aortic root was repeated in every 20 minutes throughout cardiopulmonary bypass. Antegrade cardioplegia was given through the proximal end of the safen vein grafts after each distal anastomosis of saphenous vein grafts. Proximal anastomosis were done under side clamps. Complete revascularization applied in all patients. Left internal mammary artery was used routinely in appropriate patients without left ventricle aneurysm. Neutralisation of the heparin was maintained by protamine hydrochlorure (Protamine ICN, Onko) in ratios 1:1. Demographic properties of the patients, operational data and postoperative complications were registered.

\section{STATISTICAL ANALYSIS}

SPSS 18.0 programme is used in analysing the data statistically. Qualitative data are summerised as numbers and percentage, quantitative data are summerised as mean and standart deviation (if necessary as mean; minimum; and maximum). Chi square test is used to compare the quantitative values between the two groups. In comparing quantitative data between binary groups $\mathrm{T}$ test is used in hypothetical groups and Mann Whitney $U$ test is used in nonypothetical groups. In comparing numerical measurements of more than two groups one way variance analysis is used for hypothetical ones, and Kruskal Wallis test is used for nonhypothetical ones. The statisticall magnitude level is accepted as 0.05 .

\section{RESULTS}

There were 97 patients (8.7\%) who have 35\% ejection fraction or less out of 1106 patients who underwent isolated coronary artery bypass surgery between January 2009 and December 2011 in our clinic. The mean age of group 1 was $62.37 \pm 7.6$, and the mean age of group 2 was $59.3 \pm 10.5(p=0.324)$. There were no statistically significant difference between the two groups in terms of sex, cardiovascular risk factors like diabetes mellitus
(DM), hypertension (HT), chronic obstructive pulmonary disease (COPD), left ventricle end systolic diameter and left ventricle end diastolic diameter $(p=0.682, p=0.367$, $p=0.41, p=0.809, p=0.17, p=0.816)$. The average ejection fraction was less in group 1 than group 2 ( $\mathrm{p}=$ 0.021). Preoperative demographic features of patients are listed in Table 1.

Coronary artery bypass surgery was carried on the beating heart in 3 patients in Group 1 and in 2 patients in Group 2. Left ventricle aneurysm surgery was carried in 2 patients in Group 1 and in 12 patients in Group 2. There were no statistically significant difference between the two groups in terms of demand for inotropics, demand for intraaortic balloon pump, revision (because of bleeding), atrial fibrillation, discharging intervals, intensive care unit time, cross clamp and cardiopulmonary bypass time ( $\mathrm{p}=$ $0.11, \mathrm{p}=0.809, \mathrm{p}=0.245, \mathrm{p}=0.511, \mathrm{p}=0.756, \mathrm{p}=0.987$, $p=0.889, p=0.704)$. It was found that drainage and need for blood transfusion were less in group 1 than group 2 (p $=0.049, \mathrm{p}<0.001$ ). It was detected that significant difference between the amount of drainage disappeared when the beating heart operations were excluded from two groups $(p=0.084)$. There were no statistically significant difference between the two groups in terms of mortality ( $p=0.487$ ). Intraoperative and postoperative findings of patients are listed in Table 2.

\section{DISCUSSION}

Cardiovascular surgeons have encountered more patients with left ventricle dysfunction recently because of increased number of coronary artery interventions [3]. It was of increased interest for surgical treatment of ischemic cardiomyopathy because of limited donor candidates for transplantation. Myocardial dysfunction occurs at different degrees after coronary artery bypass surgery. This situation may lead to an important problem in patients with left ventricular dysfunction. Surgical

Table 1. Preoperative demographic findings.

\begin{tabular}{cccc}
\hline & Group $1(\mathrm{n}=13)$ & Group $2(\mathrm{n}=84)$ & $\mathrm{p}$ \\
\hline Age & $62.3 \pm 7.6$ & $59.3 \pm 10.5$ & $>0.05$ \\
Male & 11 & 67 & $>0.05$ \\
Female & 2 & 17 & $>0.05$ \\
DM & 6 & 28 & $>0.05$ \\
HT & 4 & 36 & $>0.05$ \\
COPD & 1 & 5 & $>0.05$ \\
LVESD (cm) & $4.1 \pm 0.7$ & $3.9 \pm 0.5$ & $>0.05$ \\
LVEDD (cm) & $5 \pm 0.7$ & $4.9 \pm 0.4$ & $>0.05$ \\
EF (\%) & $32.2 \pm 3.8$ & $33.8 \pm 2$ & $<0.05$ \\
\hline
\end{tabular}

DM: Diabetes mellitus; HT: Hypertension; COPD: Chronic obstructive pulmonary disease; LVESD: Left ventricle end systolic diamater; LVEDD: Left ventricle end diastolic diamater; EF: Ejection fraction. 
Table 2. Intraoperative and postoperative findings of patients.

\begin{tabular}{|c|c|c|c|}
\hline & Group $1(n=13)$ & Group $2(n=84)$ & $\mathrm{p}$ \\
\hline Drainage (ml) & $376.9 \pm 99.2$ & $636.9 \pm 522.4$ & $<0.05$ \\
\hline Revision & 0 & 8 & $>0.05$ \\
\hline $\begin{array}{c}\text { Blood } \\
\text { transfusion (ml) }\end{array}$ & $246.2 \pm 145$ & $584.5 \pm 354.8$ & $<0.001$ \\
\hline IABP & 1 & 5 & $>0.05$ \\
\hline $\begin{array}{l}\text { Intensive care } \\
\text { unit time (hour) }\end{array}$ & $27.3 \pm 10.2$ & $34.1 \pm 17.9$ & $>0.05$ \\
\hline $\begin{array}{l}\text { Dhischarging } \\
\text { intervals (day) }\end{array}$ & $6.8 \pm 2.4$ & $7.4 \pm 2.9$ & $>0.05$ \\
\hline $\begin{array}{l}\text { Cross clamp } \\
\text { time (minute) }\end{array}$ & $36 \pm 19.3$ & $35.9 \pm 17.5$ & $>0.05$ \\
\hline $\begin{array}{c}\text { Total CPB } \\
\text { time (minute) }\end{array}$ & $72.6 \pm 31.3$ & $69.9 \pm 28.7$ & $>0.05$ \\
\hline $\begin{array}{l}\text { Demand for } \\
\text { inotropics }\end{array}$ & 11 & 52 & $>0.05$ \\
\hline Exitus & 1 & 3 & $>0.05$ \\
\hline
\end{tabular}

IABP: Intraaortic balloon pump; CPB: Cardiopulmonary bypass.

achievements in patients with left ventricular dysfunction allow us to take measures for myocardial dysfunction. A lot of cardioprotective methods have been attempted for reduction of myocardial dysfunction in postoperative period of coronary artery bypass surgery. Levosimendan has been used commonly for this purpose. In many studies, it was declared that levosimendan reduced myocardial dysfunction in coronary artery bypass surgery [2, 4-6]. On the contrary, in some studies, it was detected that levosimendan did not influence postoperative hemodynamic parameters and mortality in patients with left ventricular dysfunction [7]. In our study, it was detected that, there were no difference between two groups in terms of mortality even though the patients receiving levosimendan had lower ejection fraction than the patients not receiving levosimendan.

Levosimendan is a new positive inotropic drug. In some studies, it was detected that levosimendan usage increased interestingly demand for inotropics in coronary artery bypass surgery $[4,7]$. On the contrary, in a study, it was detected that levosimendan usage decreased demand for inotropics [2]. In our study, the rate of demand for inotropics was more in group 1 than group 2 but this difference was no statistically significant. In a study conducted by Tritapepe et al. it was detected that levosimendan reduced duration of intensive care unit stay in coronary artery bypass surgery [2]. In our study, duration of intensive care unit stay was less in group 1 than group 2 but this difference was not statistically significant.

Atrial fibrillation is an important cause for mortality and morbidity after coronary artery bypass surgery [8]. Levosimendan has arrythmogenic effect like other posi- tive inotropic drugs [9]. In a study of Maharaj and his colleagues, it was detected that levosimendan usage decreased incidence of atrial fibrillation in coronary artery bypass surgery [10]. On the contrary, in another study, Tek et al. detected that levosimendan usage increased incidence of atrial fibrillation in coronary artery bypass surgery [9]. In our study, there was no difference between these two groups in terms of incidence of atrial fibrillation.

We could not find a study about bleeding effect of levosimendan in coronary artery bypass surgery. Some phosphodiesterase inhibitors may increase blood loss after surgery but in our study, it was detected that the amount of drainage was less. This result might be related to the ratio of beating heart operation was higher in group 1 . Thus no difference was found between two groups regarding the amount of drainage when the beating heart operations were excluded. In our study, it was detected that need for blood transfusion was less in group 1 than group 2. These results may change with increasing number of patients so we consider that a larger multicentric study is needed. Finally, we think that levosimendan decreases need for blood transfusion in coronary artery bypass surgery.

\section{CONCLUSION}

We think that levosimendan decreases need for blood transfusion in coronary artery bypass surgery patients with left ventricular dysfunction. These results may change with increasing number of patients so we consider that a larger multicentric study is needed.

\section{LIMITATIONS OF THE STUDY}

Our study includes a small number of patients. It is a retrospective study of a single center.

\section{ACKNOWLEDGEMENTS}

We hereby like to thank Dr. Ismail Yurekli for his participation in English editing.

\section{REFERENCES}

[1] Suzer, O., Bozkurt, A.K., Suzer, A., Aykac, Z. and Barlas, A. (1996) The comparison of the inotropic effects of levosimendan and amrinone after ischemia in solated perfused guinea pig hearts. Turk Gogus Kalp Dama, 1, 5-8.

[2] Tritapepe, L., De Santis, V., Vitale, D., Guarracino, F., Pellegrini, F., Pietropaoli, P., et al. (2009) Levosimendan pre-treatment improves outcomes in patients undergoing coronary artery bypass graft surgery. British Journal of Anaesthesia, 102, 198-204. doi:10.1093/bja/aen367

[3] Maltais, S., Ladouceur, M. and Cartier, R. (2011) The 
influence of a low ejection fraction on long-term survival in systematic off-pump coronary artery bypass surgery. British Journal of Anaesthesia, 39, 122-127. doi:10.1016/j.ejcts.2010.12.022

[4] Lahtinen, P., Pitkänen, O., Pölönen, P., Turpeinen, A., Kiviniemi, V. and Uusaro, A. (2011) Levosimendan reduces heart failure after cardiac surgery: A prospective, randomized, placebo-controlled trial. Critical Care Medicine, 39, 2263-2270.

doi:10.1097/CCM.0b013e3182227b97

[5] Malliotakis, P., Xenikakis, T., Linardakis, M. and Hassoulas, J. (2007) Haemodynamic effects of levosimendan for low cardiac output after cardiac surgery: A case series. The Hellenic Journal of Cardiology, 48, 80-88.

[6] Tasouli, A., Papadopoulos, K., Antoniou, T., Kriaras, I., Stavridis, G., Degiannis, D., et al. (2007) Efficacy and safety of perioperative infusion of levosimendan in patients with compromised cardiac function undergoing openheart surgery: Importance of early use. European Journal Cardio-Thoracic Surgery, 32, 629-633.

\section{doi:10.1016/j.ejcts.2007.07.010}

[7] Kolseth, S.M., Nordhaug, D.O., Stenseth, R., Sellevold, O., Kirkeby-Garstad, I. and Wahba, A. (2009) Prophylactic treatment with levosimendan: A retrospective matchedcontrol study of patients with reduced left ventricular function. European Journal Cardio-Thoracic Surgery, 36, 1024-1030. doi:10.1016/j.ejcts.2009.05.001

[8] Maisel, W.H., Rawn, J.D. and Stevenson, W.G. (2001) Atrial fibrillation after cardiac surgery. Annals of Internal Medicine, 18, 1061-1073.

[9] Tek, M., Cavusoglu, Y., Demirustu, C., Birdane, A., Unalir, A., Gorenek, B., et al. (2010) Levosimendan and dobutamine have a similar profile for potential risk for cardiac arrhythmias during 24-hour infusion in patients with acute decompensated heart failure. Archives of the Turkish Society of Cardiology, 38, 334-340.

[10] Maharaj, R. and Metaxa, V. (2011) Levosimendan and mortality after coronary revascularisation: A meta-analysis of randomised controlled trials. Critical Care, 15, R140. oi:10.1186/cc10263 